\title{
Lung injury following pulmonary resection in the isolated, blood-perfused rat lung
}

\author{
E.A. Williams*, G.J. Quinlan*, P.B. Anning*, P. Goldstraw*, T.W. Evans*
}

Lung injury following pulmonary resection in the isolated, blood-perfused rat lung. E.A.Williams, G.J.Quinlan, P.B. Anning, P. Goldstraw, T.W. Evans. (C) ERSJournals Ltd 1999. ABSTRACT: Lung resection may be complicated by postpneumonectomy pulmonary oedema. Oxidant generation following surgery-induced ischaemia-reperfusion may be responsible.

This hypothesis was tested utilizing isolated, in situ, blood perfused rodent lungs subjected to continuous perfusion (control subjects); one lung ventilation followed by pneumonectomy (group 1); or one lung ventilation followed by reinflation of the collapsed lung (group 2).

In control subjects, no significant changes in markers of oxidant damage, oxygenation, pulmonary artery pressure or extravascular albumin extravasation were detected. In group 1 lungs, hydroxyl radical-like damage was detected in association with impaired oxygenation $(\mathbf{p}<0.05)$, and increased pulmonary artery pressure and extravascular albumin accumulation in both lungs. In group 2 , there was evidence of hydroxyl radical-like damage, and a fall in oxygenation $(p<0.05)$ occurred during one lung ventilation. There was a transient rise in pulmonary artery pressure following lung reinflation and extra vascular albumin accumulation was significantly increased in both lungs (right $>$ left, $p<0.05)$. Both changes were attenuated $(p<0.05)$ following treatment with the reactive oxygen species (ROS) scavenger superoxide dismutase (group 2a) and the nitric oxide synthase inhibitor $N^{\mathrm{G}}$ - nitro-L-arginine methyl ester (group 2b). Hydroxyl radical-like damage was undetectable following nitric oxide synthase inhibition.

Oxidant stress may contribute to the pathologies seen in this model of lung injury. Eur Respir J 1999; 14: 745-750.
*Unit of Critical Care ${ }^{*}$ Dept of Thoracic Surgery, Imperial College School of Medicine and Royal Brompton Hospital, London, UK.

Correspondence: T.W. Evans

Intensive Care Unit

Royal Brompton Hospital

Sydney Street

London SW3 6NP

UK

Fax: 441713518524

Keywords: Hydroxyl radical ischaemia reperfusion injury peroxynitrite

postpneumonectomy pulmonary oedema reactive oxygen species

Received: December 291998

Accepted after revision May 251999

This work was supported by the British Lung Foundation, the Dunhill Medical Trust and the British Heart foundation.
Pulmonary oedema following lung resection represents one cause of the acute respiratory distress syndrome (ARDS) in adults [1-3], and complicates $4-7 \%$ of pneumonectomies and $1-7 \%$ of lobectomies [4]. Ischaemia-reperfusion (I-R) injury $[5,6]$ is a possible cause, and is known to occur following the rapid re-expansion of a collapsed lung, or after pulmonary transplantation $[7,8]$. I-R is mediated at least in part by the generation of toxic, reactive oxygen species (ROS) [1]; and evidence of oxidative damage has been found recently in patients with ARDS precipitated by a wide variety of conditions [9-11]. Secondly, it is now recognized that pulmonary vascular control and integrity may be modulated by the release of NO [12] and in animal models of I-R-mediated lung injury, inhaled NO may be either protective or damaging, depending upon dose and time of administration [13]. Furthermore, inhibition of NO synthase (NOS) in differing experimental circumstances has shown conflicting roles for endogenous NO in the modulation of ROS-induced damage $[14,15]$. The aims of this investigation were therefore two-fold. First, to investigate the role of I-R in generating the pulmonary vascular injury that occurs following lung resection using an isolated, blood-perfused rodent model. Second, the effects of ROS and NO in modulating this process were evaluated using the ROS scavenger super- oxide dismutase (SOD) and the NO synthase inhibitor $N^{\mathrm{G}}$ nitro-L-arginine methyl ester (L-NAME) respectively.

\section{Methods and materials}

Protocols were designed to investigate the hypothesis that the clinical techniques of one lung ventilation (OLV) followed either by pneumonectomy or reinflation might result in lung injury, quantified by measuring changes in pulmonary artery pressure (PAP), extravascular albumin accumulation (EAA) and oxygenation index. Specific evidence of ROS generation was sought by measuring levels of D-ortho- and D-meta-tyrosine formed from added Dphenylalanine, indicating evidence of hydroxyl $(\cdot \mathrm{OH})$-like damage.

\section{Preparation}

All experimental protocols were carried out in accordance with the Animals (Scientific Procedures) Act 1986 (UK). An in situ ventilated, blood-perfused rat lung preparation described in full elsewhere [16] was used throughout. Briefly, male Wistar rats (175-225 g) were 
anaesthetized (pentobarbitone $60 \mathrm{mg} \cdot \mathrm{kg}^{-1}$ i.p.), the trachea cannulated and ventilation commenced (gas $21 \% \mathrm{O}_{2}, 5 \%$ $\mathrm{CO}_{2}$, balance nitrogen $\mathrm{N}_{2}$; tidal volume $2.5 \mathrm{~mL}$, frequency 60 cycles $\cdot \mathrm{min}^{-1}$ with positive end-expiratory pressure (PEEP) $2 \mathrm{cmH}_{2} \mathrm{O}$ ).

Exsanguination via the abdominal aorta was then performed following heparinization ( $30 \mathrm{mg} \cdot \mathrm{kg}$ body weight ${ }^{-1}$ ), the blood placed in a reservoir at $40^{\circ} \mathrm{C}$, and supplemented with $4 \%$ bovine serum albumin (BSA) in $0.9 \%$ normal saline to a volume corresponding to the in vivo circulating blood volume. The lungs were exposed and a loose ligature placed around the right main bronchus in experiments requiring OLV, and a snugger applied to allow reversible isolation of the right bronchial tree when required. Cannulae were inserted into the pulmonary artery (PA) and left atrial (LA) appendage. The completed circuit consisted of the LA cannula, a pressure transducer, $20 \mathrm{~mL}$ reservoir, roller pump, PAP transducer and PA cannula. The lungs were perfused at $18 \mathrm{~mL} \cdot \mathrm{min}^{-1}$ Left atrial pressure (LAP), PAP and airway pressure (Paw) were recorded continuously. Free drainage of blood from the LA to blood reservoir ensured that changes in PAP were directly proportional to, and therefore representative of changes in pulmonary vascular resistance. Blood gas tensions were analysed at three time points during each experiment and $\mathrm{pH}$ maintained in the physiological range by addition of small aliquots of sodium bicarbonate as appropriate.

\section{Experimental methods}

Extravascular albumin accumulation. ${ }^{125}$ I-human serum albumin (HSA) $(15 \mathrm{~mL}, \sim 18.5 \mathrm{MBq})$ was added to the perfusate during the equilibration period (see Experimental Protocols). At the end of each experiment (120 min) $1 \mathrm{~mL}$ of blood perfusate was collected for the estimation of radioactivity. Residual radioactivity was flushed out by circuit perfusion with $75 \mathrm{~mL}$ of $4 \%$ BSA in $0.9 \%$ normal saline at a perfusion pressure two thirds of the final PAP, and confirmed by direct comparison of counts in $1 \mathrm{~mL}$ of the final perfusate with background levels of activity, measured using an empty cuvette. Paired tissue samples from both lungs were weighed after gentle blotting, placed in cuvettes and together with the perfusate samples counted for a period of $10 \mathrm{~min}$ per cuvette. EAA was calculated as the ratio of counts per min (cpm) per g (lung) to cpm per $\mathrm{mL}$ (blood). For studies in which a right pneumonectomy was carried out comparisons of EAA were made between the resected lung and the left (i.e. remaining) lung.

Measurement of reactive oxygen species production. Evidence for production of the hydroxyl radical was sought by utilizing its ability to hydroxylate phenylalanine [8]. Low molecular mass constituents were separated from plasma samples by size exclusion, freeze-dried and derivatized [11]. D-meta- and D-orthotyrosine were detected based on their retention times and characteristic mass spectra, by positive ion electron impact gas chromatography mass spectrometry. D- and L-isomers were resolved by use of a chiral gas chromatography (GC) column.

\section{Experimental protocols}

Stabilization period: an initial period of 30 min was included in all protocols to stablize the preparation. During this time $15 \mathrm{mg}$ D-phenylalanine and $15 \mathrm{~mL}$ of iodinated human serum albumin were added to the perfusate.

Control Group: after stabilization, lungs were subjected to 120 min of continuous ventilation and perfusion with no intervention. PAP was analysed for changes from baseline at 60 and $120 \mathrm{~min}$. Baseline perfusate oxygen tension was measured at 0 (baseline), 50 and $110 \mathrm{~min}$. Paired $0.5 \mathrm{~mL}$ samples of perfusate were collected at $0,50,70$ and 120 min for later assay of markers of ROS production. Circuit volume was maintained at each sampling by replacement with equivalent volumes of BSA. At $120 \mathrm{~min}$ (end-point), tissue samples were resected from each lung for gamma activity estimation (concurrent with $1 \mathrm{~mL}$ samples of circuit perfusate) and calculation of EAA.

Group 1: effect of one lung ventilation and right pneumonectomy on lung injury. After 30 min stabilization, the right lung was collapsed but the pulmonary vessels were not ligated and OLV performed for $60 \mathrm{~min}$. The pulmonary artery, vein and bronchus were ligated at the hilum and the right lung resected. Ventilation and perfusion of the left lung continued for a further $60 \mathrm{~min}$. EAA was measured in both the resected and contralateral lungs. To control for the effects of volotrauma, tidal volume was reduced during OLV to maintain constant Paw. The indices of lung injury that were measured were identical in timing and nature to those performed in control subjects.

Group 2: effect of collapse-reinflation of the right lung on lung injury. Preliminary studies revealed that reinflation of right lung tissue following partial resection could not be reliably undertaken whilst controlling for the variable effects of volotrauma and reinflation. Thus, following 30 min stabilization the collapsed right lung was reinflated (without resection of tissue) and ventilation and perfusion of both lungs continued for a further $60 \mathrm{~min}$. The indices of lung injury that were measured were identical in timing and nature to those performed in control subjects and group 1 animals.

Protocol 2a: effect of superoxide dismutase on pulmonary artery pressure and lung injury following collapse-reinflation of the right lung. During the stabilization period, 4,400 IU of freshly prepared SOD dissolved in $200 \mu \mathrm{L} 0.9 \% \mathrm{NaCl}$ was added to the perfusate reservoir, prior to the collapse-reinflation procedure. The indices of lung injury that were measured were identical in timing and nature to those performed in the control subjects, and in groups 1 and 2 animals. The protocol for group 2 (right lung reinflation) was chosen for this aspect of the study as such animals had shown the most marked degree of lung injury.

Group 2b: effect of L-NAME on pulmonary artery pressure and lung injury following collapse-reinflation of the right lung. During the $30 \mathrm{~min}$ stabilization period, LNAME dissolved in $200 \mu \mathrm{L} 0.9 \% \mathrm{NaCl}$ was added to the perfusate to produce a final circulating concentration of 1 $\mathrm{mM} \cdot \mathrm{L}^{-1}$ (chosen as pilot studies using lower concentrations failed to show a consistent effect). Collapse-reinflation of the right lung was then performed as in Group 2 animals and identical parameters to those in control subjects, groups 1,2 and 2a were measured. 

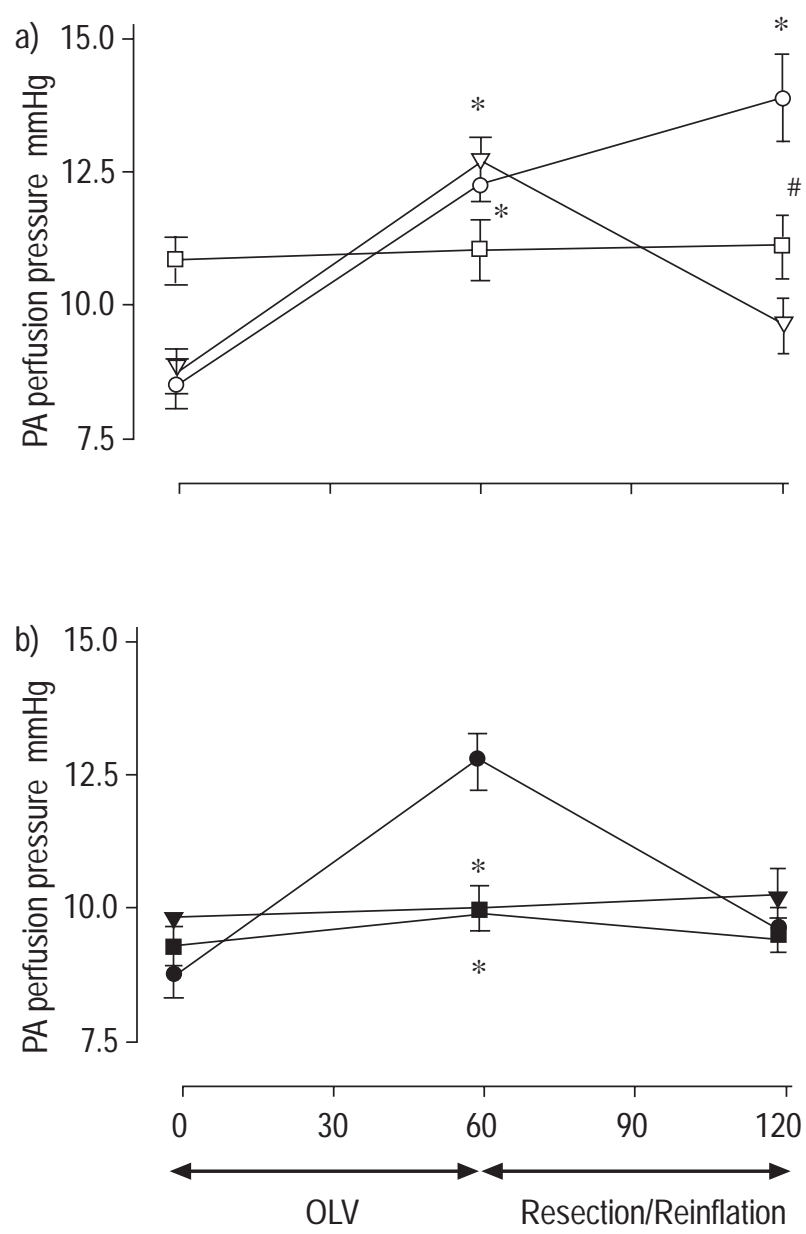

Fig. 1. - Changes in pulmonary artery (PA) pressure (PAP). a) PAP measured at 0,60 and $120 \mathrm{~min}$ in rats subjected to $120 \mathrm{~min}$ of continuous perfusion (o) (control subjects, $n=12$ ); right pneumonectomy $(O)$ (group $1, \mathrm{n}=10)$; or one lung ventilation (OLV) followed by reinflation $(\nabla)$ (group 2, n=5).*: denotes $\mathrm{p}<0.05$ for comparative statistics within the same group; \#: denotes $\mathrm{p}<0.05$ for between group comparisons at matched time points. b) PAP measured at 0,60 , and $120 \mathrm{~min}$ in rats subjected to OLV followed by reinflation (O) (group 2, n=5); OLV followed by reinflation following the addition of superoxide dismutase (SOD) 4,400 IU (ם) (group 2a, n=7); or OLV followed by reinflation following the addition of $N^{\mathrm{G}}$-nitro-L-arginine methylester (L-NAME) (final concentration $\left.1 \mathrm{mmol} \cdot \mathrm{L}^{-1}\right)(\boldsymbol{\nabla})($ group $2 \mathrm{~b}, \mathrm{n}=7)$. *: denotes $\mathrm{p}<0.05$ compared to the absence of inhibitor. All data are presented as mean \pm SEM

\section{Results}

Control animals $(n=12)$ showed no significant changes in PAP, oxygenation or EAA for the duration of the experiment. Indices of $\cdot \mathrm{OH}-$ like activity were not detectable (fig. 1-4).

Group 1 ( $\mathrm{n}=10$, one lung ventilation followed by right pneumonectomy). Baseline PAP $(8.50 \pm 0.46 \mathrm{mmHg}, \mathrm{n}=10)$ rose acutely at the time of pneumonectomy (mean elevation $3.75 \pm 0.31 \mathrm{mmHg}$ ) and continued to increase until $120 \mathrm{~min}$ (mean elevation $5.37 \pm 0.82 \mathrm{mmHg}$ ), $\mathrm{p}<0.01$ c.f. baseline, (fig. 1a). Oxygenation fell during OLV (oxygen tension in arterial blood) $\left(\mathrm{Pa}_{\mathrm{a}} \mathrm{O}_{2} 25.6 \pm 1.1\right.$ versus $22.6 \pm 1.2 \mathrm{kPa}$ respectively, $\mathrm{p}=\mathrm{NS})$ and was significantly reduced following pneumonectomy $\left(\mathrm{Pa}_{\mathrm{a}} \mathrm{O}_{2} 25.6 \pm 1.1\right.$ baseline versus $20.7 \pm 0.7 \mathrm{kPa}, \mathrm{p}<0.05$ ) (fig. 2). EAA was significantly increased in both the resected and contra-

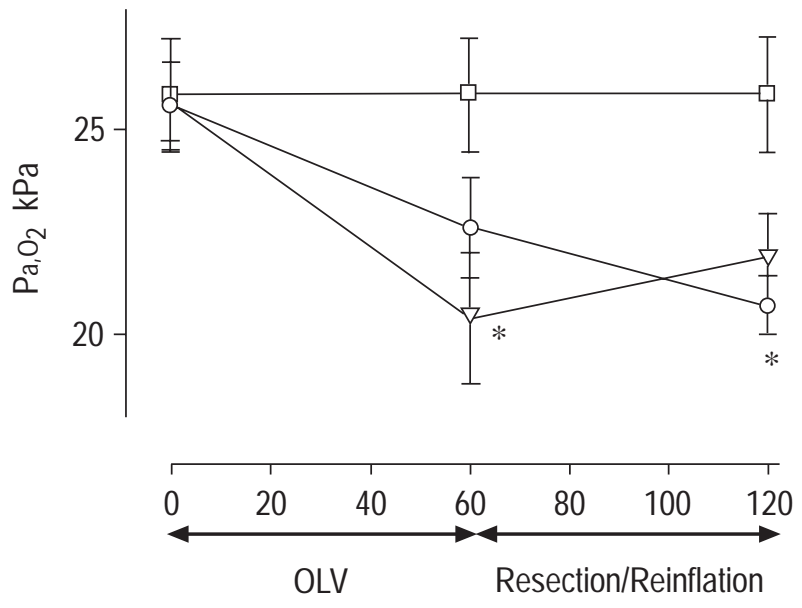

Time $\min$

Fig. 2. - Changes in oxygenation. Oxygenation (oxygen tension in arterial blood $\left.\left(\mathrm{Pa}, \mathrm{O}_{2}\right) \mathrm{kPa}\right)$ measured at 0,50 and $110 \mathrm{~min}$ in rats subjected to $120 \mathrm{~min}$ continuous perfusion $(\square)$ (control subjects, $n=12$ ); right pneumonectomy $(\bigcirc)$ (group $1, n=10)$; or one lung ventilation (OLV) followed by reinflation $(\nabla)$ (group $2, \mathrm{n}=5$ ). *: denotes $\mathrm{p}<0.05$ c.f. baseline oxygenation. Data are presented as mean \pm SEM.

lateral lungs compared to corresponding control subjects (EAA for resected right lung $0.42 \pm 0.02 \mathrm{cpm} \cdot \mathrm{g}$ lung tissue $^{-1} \cdot \mathrm{mL}$ blood $^{-1}$ versus $0.21 \pm 0.03$ for left lung, $\mathrm{p}<0.05$; control EAA $0.054 \pm 0.01$ and $0.055 \pm 0.00$ for right and left lung respectively, (fig. 3a). Elevated levels of D-ortho- and D-meta-tyrosine were detected at 50, 70 and $120 \mathrm{~min}$ (which were significantly increased for Dortho-tyrosine after $70 \mathrm{~min}, \mathrm{p}<0.05)$ following pneumonectomy $(n=3)$ providing evidence of $\cdot \mathrm{OH}$-like mediated damage (fig. 4).

Group $2(n=5$, one lung ventilation followed by right lung reinflation). There was a significant, progressive and acute rise in PAP following reinflation of the right lung (mean elevation $3.9 \pm 0.5 \mathrm{mmHg}, \mathrm{p}<0.05$ ). PAP returned to baseline within $10 \mathrm{~min}$ and remained unchanged from baseline at $120 \mathrm{~min}$ (mean elevation $0.8 \pm 0.1 \mathrm{mmHg}, \mathrm{p}>0.05$, (fig. 1a)). Oxygenation fell during OLV $(25.68 \pm 0.96 \mathrm{kPa}$ baseline versus $20.37 \pm 1.60 \mathrm{kPa}, \mathrm{p}<0.05)$, and showed a small rise on return to dual lung ventilation to $21.8 \pm 1.1$ $\mathrm{kPa}$ although this did not reach baseline levels (fig. 2). EAA was significantly increased in both lungs (right lung $0.56 \pm 0.06$, left lung $0.38 \pm 0.05$ ) compared to control values (right lung $0.054 \pm 0.01$, left lung $0.055 \pm 0.00$, $\mathrm{p}<0.01$, fig. 3a). The increase in EAA was significantly greater in the left lung following right lung reinflation compared to the left lung following pneumonectomy $(0.36 \pm 0.05$ versus $0.21 \pm 0.03$, $\mathrm{p}<0.05$, (fig. $3 \mathrm{a})$ ). Evidence of $\cdot \mathrm{OH}$-like damage was detectable at 50,70 and $120 \mathrm{~min}$; peak concentrations for D-ortho-tyrosine $(\mathrm{p}<0.05)$ being measured at the $70 \mathrm{~min}$ timepoint $(10 \mathrm{~min}$ following reinflation/reperfusion). Mean concentrations following correction for dilution are shown in figure 4.

Group $2 \mathrm{a}(\mathrm{n}=7$, effect of superoxide dismutase on lung injury following collapse-reinflation of the right lung). Baseline PAP $(9.3 \pm 0.4 \mathrm{mmHg}, \mathrm{n}=7)$ was unaffected by the addition of SOD, and following reinflation, at 60 and 120 min, no significant elevations in PAP were observed $(9.9 \pm 0.3$ and $9.4 \pm 0.4 \mathrm{mmHg}$ respectively, (fig. $1 \mathrm{~b})$. EAA 
was significantly lower for both lungs (right lung $0.15 \pm 0.02$, left lung $0.10 \pm 0.01$ ) compared to the values obtained for right lung reinflation alone (group 2 animals, right lung $0.56 \pm 0.06$, left lung $0.38 \pm 0.05$, $\mathrm{p}<0.01$, fig. $3 \mathrm{~b})$ ). The addition of 4,400 IU SOD and 120 min perfusion only caused no significant change in EAA (right lung $0.13 \pm 0.07$, left lung $0.11 \pm 0.05, n=3$ ) compared to $120 \mathrm{~min}$ continuous perfusion alone (right lung $0.054 \pm$ 0.00 and left lung $0.055 \pm 0.01, \mathrm{p}>0.05$ ). No D-ortho- nor D-meta-tyrosine were detectable in perfusate samples, suggesting that $\cdot \mathrm{OH}-$ like damage was inhibited by SOD administration (differences almost reached significance at $70 \mathrm{~min}$ for D-ortho-tyrosine, $\mathrm{p}=0.052$ and D-meta-tyrosine, $\mathrm{p}=0.082$, (fig. 4)).

Protocol $2 \mathrm{~b}\left(\mathrm{n}=7\right.$, effects of $N^{\mathrm{G}}$-nitro-L-arginine methyl ester on lung injury following collapse-reinflation of the right lung). Addition of L-NAME had no discernable effect on baseline PAP $(9.8 \pm 0.02 \mathrm{mmHg}, \mathrm{n}=7)$. Following reinflation there was no significant elevation in PAP $(10.0 \pm$ $0.4 \mathrm{mmHg}$ and $10.3 \pm 0.5 \mathrm{mmHg}$ at 60 and $120 \mathrm{~min}$ respectively, both $\mathrm{p}>0.05$, fig. 1)). EAA was significantly lower

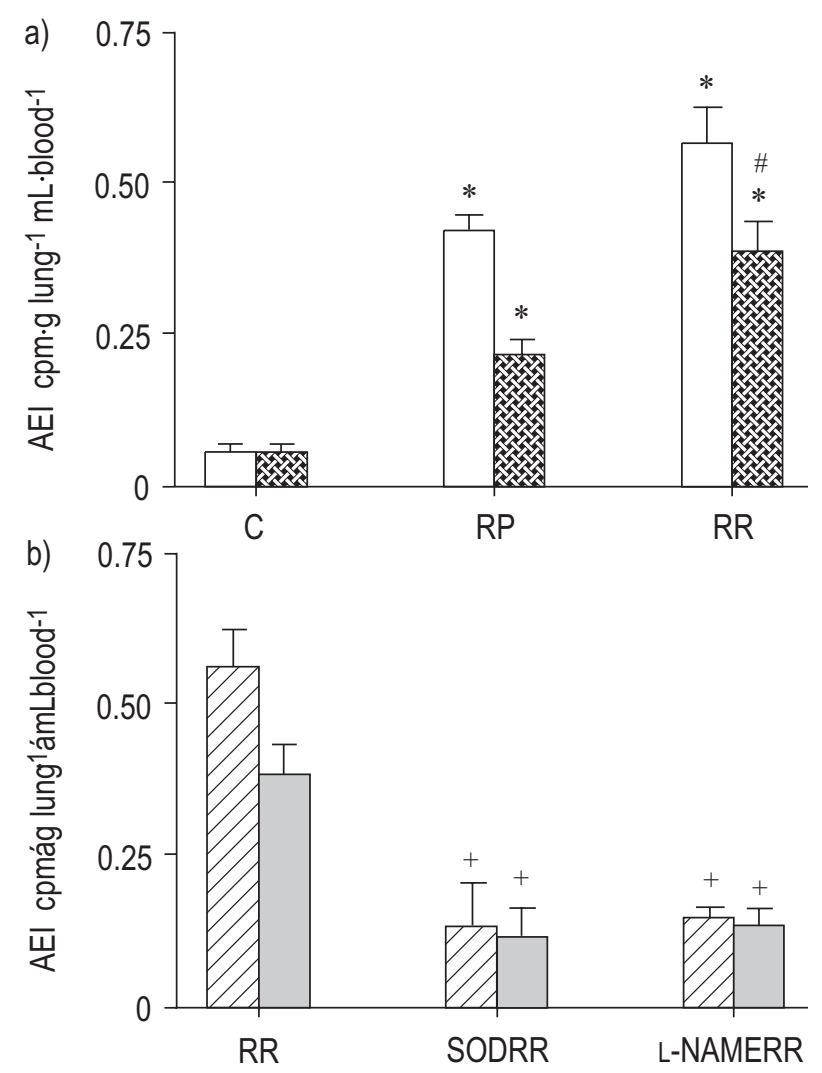

Fig. 3. - Changes in extravascular albumin accumulation (EAA). a) EAA measured in the right $(\square)$ and left (ख) lungs of rats subjected to 120 min continuous perfusion (C) (control subjects, $\mathrm{n}=12$ ); right pneumonectomy (RP) (group $1, \mathrm{n}=10$ ); or one lung ventilation (OLV) followed by reinflation (RR) (group $2, n=5$ ). *: denotes $\mathrm{p}<0.05 \mathrm{cf}$ controls, $^{\#}$ : denotes $\mathrm{p}<0.05$, comparing RR with corresponding RP. EAA data obtained from the resected right lung was compared with the left lung at $120 \mathrm{~min}$. b) EAA measured in the right $(\mathbb{Z})$ and left $(\square)$ lungs of rats subjected to OLV and reinflation (RR) (group 2; OLV and reinflation following the addition of superoxide dismutase (SOD) 4.400 IU (SODRR) (group 2a); or OLV and reinflation following the addition of $N^{\mathrm{G}}$-nitro-L-arginine methyl ester (L-NAME) (L-NAMERR) (to final concentration $1 \mathrm{mmol} \cdot \mathrm{L}^{-1}$ group $\left.2 \mathrm{~b}\right) .^{+}:$denotes $\mathrm{p}<0.05$ c.f. corresponding RR side. AEI: albumin escape index; cpm: counts per minute. Data are presented as mean and SEM. for both lungs compared to values obtained for right lung reinflation alone (right lung $0.15 \pm 0.02$, left lung $0.13 \pm$ $0.03, \mathrm{p}<0.001$, (fig. $3 \mathrm{~b}$ ). No D-ortho- or D-meta-tyrosine was detectable in perfusate samples, again suggesting that $\mathrm{OH}$-like damage was inhibited by L-NAME (differences almost reached significance at $70 \mathrm{~min}$ for D-ortho-tyrosine, $\mathrm{p}=0.052$, and for $\mathrm{D}-\mathrm{meta}$-tyrosine, $\mathrm{p}=0.082$, (fig. 4)).

\section{Discussion}

In this study, OLV followed by pneumonectomy caused a sustained rise in PAP, a fall in oxygenation index, a rise in EAA, and evidence of .OH-like damage. By contrast, reinflation of the right lung following OLV induced transient increases in PAP and oxygenation. EAA was again increased, but to a significantly greater extent in the contralateral lung. Evidence of $\cdot \mathrm{OH}$-like damage was also detectable, peaking at $70 \mathrm{~min}$. Both SOD and L-NAME prevented the increases in PAP and EAA seen after OLV, and appeared to inhibit $\cdot \mathrm{OH}$-like damage.

As in previous studies published by others [17], PAP remained stable in control animals. By contrast, group 1 (pneumonectomy) animals displayed an acute rise in PAP at the time of ligation of the pulmonary vessels which was sustained, and continued to increase gradually over the following $60 \mathrm{~min}$. Early experimental work on the immediate effects of lung excision in anaesthetized dogs showed PAP increased transiently, with variable changes in cardiac output [18]. Clinically, no increase in PAP is observed, at rest following pneumonectomy in young adults [19]. The current study also revealed an acute, but transient rise in PAP following reinflation of the right lung (group 2), presumably due to vasoactive effects of ROS or other inflammatory mediators generated during OLV. The influence of these changes in PAP and therefore hydrostatic forces on EAA is difficult to assess, but the rise in PAP alone was probably insufficient in itself to

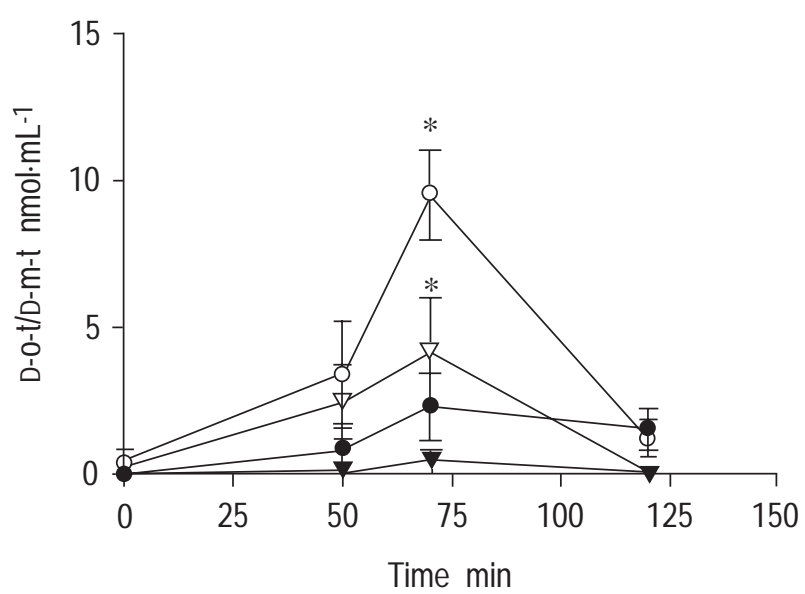

Fig. 4. - Changes in concentration of D-ortho-tyrosine. Changes measured at sequential timepoints $(0,50,70$, and $120 \mathrm{~min})$ for; $\mathrm{O}$ : right pneumonectomy (RP) (group 1); and $\nabla$ : right reinflation (RR) (group 2 protocols, together with d-meta-tyrosine concentrations for; $\mathrm{O}$ : RP; and $\boldsymbol{\nabla}$ : $R R$ at the same timepoints $(n=3$ in each case). Markers were not detectable in control subjects, or in the protocols in which superoxide dismutase or $N^{\mathrm{G}}$-nitro-L-arginine methyl ester were added and are therefore not represented here. *: denotes $\mathrm{p}<0.05$ when compared with controls. D-o-t/D-m-t: D-ortho-tyrosine/D-meta-tyrosine. Data are presented a mean \pm SEM. 
induce vascular damage. Moreover, in the current study, EAA was greatest in the (resected) right lungs of group 2 animals, which were presumably subjected to hypoperfusion if not absolute ischaemia during OLV.

A predictable fall in oxygenation occurred in both group 1 and 2 animals during OLV. However, oxygenation was further impaired following removal of the right lung in group 1, whereas some recovery occurred following reinflation without resection (group 2). In this model therefore, gas exchange is impaired in the contralateral lung for at least $60 \mathrm{~min}$ following collapse-reinflation. Several studies using small animal, isolated lung preparations to investigate the effects of both warm and cold ischaemic injury have also shown significantly impaired oxygenation on reperfusion of the isolated lung [20,21], although few investigated any effect on the contralateral lung. Impaired oxygenation under the former circumstances has been shown to correlate with measurable changes in lung permeability, neutrophil infiltration and production of ROS: all of which are implicated in the pathophysiology of clinical ARDS [22].

Compared to time-matched controls, a marked increase in EAA was noted in both lungs following collapse-resection (group 1) and after collapse reinflation (group 2) of the right lung (fig. 3). In both cases, EAA was greater in the right lung. This implies firstly, that hypoperfusion (if not frank ischaemia) alone may induce vascular injury. Secondly, as EAA rose further in both lungs (right>left) following right lung reinflation, reperfusion injury may have excerbated any injury attributable to hypoperfusion alone. Importantly, in the ventilated rat lung reperfusion is unnecessary for lipid peroxidation to occur during an ischaemic insult [23], and experimental studies concerning optimization of lung preservation have demonstrated that injury occurs during the storage/ischaemic phase as well as on reperfusion [24].

ROS are formed during reperfusion injury, although their precise source remains unknown. This study sought evidence of $\cdot \mathrm{OH}$-like mediated damage by measuring $\mathrm{D}-$ ortho- and D-meta-tyrosine which are specific markers formed when D-phenylalanine becomes hydroxylated. They were identified in both the collapse-resection (group 1) and collapse-reinflation (group 2) animals, but not in control subjects, implicating a role for ROS in the rise in EAA. Interestingly, these metabolites were identified at 50 min, prior to reinflation/resection of the lung, indicating that ROS production also occurs during the hypoperfusion of OLV in this model. However, why levels of D-ortho- and D-meta-tyrosine were greatest in group 1 animals, whereas EAA was highest in group 2 is unclear.

Addition of the ROS scavenger SOD and the NOS inhibitor L-NAME in separate protocols (groups $2 \mathrm{a}$ and $2 \mathrm{~b}$ ) prevented the acute rise in PAP that occurred on reinflation/reperfusion of the collapsed right lung. However, addition of either SOD or L-NAME immediately prior to reperfusion (i.e. after the period of hypoperfusion/ ischaemia), did not significantly inhibit the reperfusioninduced rise in PAP, further supporting the authors' contention that ROS are produced during hypoperfusion/ ischaemia (data not shown). Neither agent influenced resting PAP. In previous studies using this preparation, increased pulmonary artery pressure and no change in PAP have been reported in response to NOS inhibition [25, 26]. Similar findings in the rabbit lung suggest that NO modulates pulmonary vascular reactivity in the presence of blood. Further, SOD has been shown previously to prevent the augmentation in hypoxic pulmonary vasodilation observed following I-R in the same model [13, 27]. Lastly, both SOD and L-NAME were independently associated with a decrease in lung reperfusion injury as assessed by EAA. Protection by SOD in this study implicates superoxide as a key intermediate in causing the damage detected. Superoxide is known to rapidly interact with NO to produce peroxynitrite, which degenerates to form an $\cdot \mathrm{OH}-\mathrm{like}$ species under acid conditions. Peroxynitrite itself displays many cytotoxic effects, including lipid peroxidation of biological membranes, sulphydryl oxidation of proteins and nitration of specific amino acids [28]. The rate of reaction of superoxide with NO is approximately three times faster than its reaction with SOD and thirty times faster than the reaction of $\mathrm{NO}$ with oxyhaemoglobin [29]. Under pathological conditions where high levels of superoxide are present, the reaction may be so rapid that endogenous SOD may be insufficient to prevent peroxynitrite formation. Thus, superoxide generation may decrease NO concentrations, favouring an increase in arterial tone and formation of peroxynitrite accounting for the resultant tissue injury. Decreased NO concentration favours the Fenton reaction if redox active iron is present, thereby producing hydroxyl radicals and hydroxylations via a second pathway. A previous in vivo study in which inhaled NO given at the time of reperfusion increased injury that could be prevented by the addition of SOD lends partial credence to this hypothesis [30]. The protective effect afforded by inhaled NO against pulmonary oedema formation in various models, including the isolated perfused rat lung, suggests a different mechanism of action for NO at this site [31]. These opposing findings illustrate the diversity of action and interaction of $\mathrm{NO}$, under differing conditions.

In the current study, $\cdot \mathrm{OH}$-like oxidative modification of marker molecules was found following reperfusion, as well as during ischaemia. However, no trace of these markers could be found in preparations treated with SOD and LNAME, implying the protection that they afforded was mediated via the inhibition of a common intermediate, the effects of which resulted in hydroxylation of D-phenylalanine.

In summary, these experiments show that both $N^{\mathrm{G}}$-nitroL-arginine methyl ester and superoxide dismutase are protective against lung injury occurring following collapse-reinflation of the lung. It is speculated that peroxynitrite may be the source of hydroxyl-like species in this model of lung injury.

\section{References}

1. Zeldin RA, Normandin D, Landwing D, Peters RM. Postpneumonectomy pulmonary edema. $J$ Thorac Cardiovasc Surg 1984; 43: 323-326.

2. Shapira OM, Shahain MD. Postpneumonectomy pulmonary edema. Ann Thorac Surg 1993; 56: 190-195.

3. Bernard GR, Artigas A, Brigham KL, et al. The American-European Consensus Conference on ARDS. Am J Rev Respir Crit Care Med 1994; 149: 818-824.

4. Turnage WS, Lunn JJ. Postpneumonectomy pulmonary edema. A retrospective analysis of the associated variable. Chest 1993; 103: 1646-1650. 
5. Adkison D, Hollwarth ME, Benoit JN, Parks DA, McCord JM, Granger DN. Role of free radicals in ishemia-reperfusion injury to the liver. Acta Physio Scand Suppl 1986; 126: 101-108.

6. McCord JM. Oxygen-derived radicals: a link between reperfusion injury and inflammation. Fed Proc 1987; 46: 2402-2406.

7. Katz A, Oldman KT, Guice KS, Coran AG. Oxidised glutathione as a marker of ischemia reperfusion associated with single lung transplantation. J Am Colt Surg 1995; 180: 25-32.

8. Kaur H, Fagerheim I, Grootveld M, Puppo A, Halliwell B. Aromatic hydroxylation of phenylalanine as an assay for hydroxyl radicals: application to activated human neutrophils and to the heme protein leghemoglobin. Anal Biochem 1988; 172: 360-367.

9. Cochrane CG, Spragg R, Revak SD. Pathogensis of the adult respiratory distress syndrome: evidence of oxidant activity in bronchoalveolar lavage fluid. $J$ Clin Invest 1983; 71: 751-761.

10. Lefevre GF, Brunet $\mathrm{C}$, Bonneau $\mathrm{C}$, et al. Human polymorphonuclear leukocyte metabolism and lipo-peroxidation during adult respiratory distress syndrome treated by extracorporeal carbon dioxide removal. Pathophysiology 1994; 1: 13-19.

11. Quinlan GJ, Lamb NJ, Evans TW, Gutteridge JMC. Plasma fatty acid changes in patients with adult respiratory distress syndrome. Crit Care Med 1996; 24: 241-246.

12. Moncada S. Nitric oxide gas: mediator, modulator, and pathophysiologic entity. J Lab Clin Med 1992; 120: 187191.

13. Eppinger MJ, Ward PA, Jones ML, Boiling SF, Deeb GM. Disparate effects of nitric oxide on lung ischaemiareperfusion injury. Ann Thorac Surg 1995; 60: 11691176.

14. Feigi E. EDRF - a protective factor? Nature 1988; 331 490-491.

15. Clancy RM, Leszczynska-Piziak J, Abramson SB. Nitric oxide, an endothelial cell relaxation factor, inhibits neutrophil superoxide production via a direct effect on NADPH oxidase. J Clin Invest 1992; 90: 1116-1121.

16. Messent M, Griffiths MGD, Evans TW. Pulmonary vascular reactivity and ischaemia-reperfusion injury in the rat. Clinical Science 1993; 85: 71-75.

17. Czartolomna J, Voelkel NF, Chang SW. Permeability characteristics of isolated perfused rat lungs. $J \mathrm{Appl}$ Physiol 1991; 70: 1854-1860.

18. Long JH, Wester MR, Oppenheimer MJ. Immediate cardiovascular and respiratory adjustments to pneumonectomy. Journal of Thoracic Surgery. 1949; 18: 629634.

19. Cournand A, Riley RL, Himmelstein A. Pulmonary circulation and ventilation-perfusion relationships after pneumonectomy. Journal of Thoracic Surgery 1950; 19: $80-8$.

20. Fukuse T, Hirata T, Yokomise H, et al. Attenuation of ischaemia reperfusion injury by human thioredoxin. Thorax 1995; 50: 387-391.

21. Matsuzaki Y, Waddell TK, Puskas JD, et al. Amelioration of post-ischemic lung reperfusion injury by prostaglandin E1. Am Rev Respir Dis 1993; 148: 882-889.

22. Pittet JF, Mackersie RC, Martin TR, Matthay MA. Biological markers of acute lung injury: prognostic and pathogenetic significance. Am J Respir Crit Care Med 1997; 155: 1187-1205.

23. Fisher AB, Dodia C, Tan ZT, Ayene I, Eckenhoff RG. Oxygen-dependent lipid peroxidation during lung ischaemia. J Clin Invest 1989; 88: 674-679.

24. Haniuda M, Dresler CM, Mizuta T, Cooper JD, Patterson GA. Free radical-mediated vascular injury in lungs preserved at moderate hypothermia. Ann Thorac Surg 1995; 60: 1376-1381.

25. Archer SL, Peterson D, Nelson DP, Kelly EG, Eaton JW, Weir EK. Oxygen radicals and antioxidant enzymes alter pulmonary vascular reactivity in the rat lung. $J$ Appl Physiol 1989; 66: 102-111.

26. Liu SF, Crawley DG, Barnes PJ, Evans TW. Endotheliumderived relaxing factor inhibits hypoxic pulmonary vasoconstriction in rats. Am Rev Respir Dis 1991; 143: 32-37.

27. Koyama I, Toung TJK, Rogers MC, Gurtner GH, Traystman RJ. $\mathrm{O}_{2}$ radicals mediate reperfusion injury in ischemic $\mathrm{O}_{2}$-ventilated canine pulmonary lobe. $J$ AppI Physiol 1987; 63: 111-115.

28. Haddad IY, Ishiripoulos H, Holm BA, Beckman JS, Baker JR, Matalon S. Mechanisms of peroxynitrite induced lung injury to pulmonary surfactants. Am J Physiol 1993; 265: 555-564.

29. Beckman JS, Chen J, Ischiropoulos H, Crow JP. Oxidative chemistry of peroxynitrite. Methods Enzymol 1994; 233: 229-240.

30. Jackson RM, Veal CF. Re-expansion, re-oxygenation, and re-thinking. Am J Med Sci 1989; 298: 44-50.

31. Guidot DM, Repine MJ, Hyberston BM, Repine JE. Inhaled nitric oxide prevents neutrophil-mediated oxygen radical-dependent leak in isolated rat lungs. Am J Physiol 1995; 269: L2-L5. 